\title{
Mercury isotopic characterisation in Antarctic Giant Petrel organs and HgSe nanoparticles
}

\author{
SILVIA QUEIPO-ABAD ${ }^{1}$, ZOYNE PEDRERO ZAYAS ${ }^{1}$, \\ CLAUDIA MARCHAN MORENO ${ }^{1}$, KHOULOUD EL \\ HANAFI $^{1}$, YVES CHEREL ${ }^{2}$, PACO BUSTAMANTE ${ }^{3}$ AND \\ DAVID AMOUROUX ${ }^{4}$ \\ ${ }^{1}$ Universite de Pau et des Pays de l'Adour, E2S UPPA, CNRS, \\ IPREM, Institut des Sciences Analytiques et de Physico-chimie \\ pour l'Environnement et les matériaux \\ ${ }^{2}$ CEBC - CNRS-La Rochelle Université \\ ${ }^{3}$ LIENSs - CNRS-La Rochelle Université \\ ${ }^{4}$ CNRS, Université de Pau et Pays de l'Adour, E2S UPPA, \\ IPREM
}

Presenting Author: silvia.queipo-abad@univ-pau.fr

Methylmercury (MeHg) is considered the most neurotoxic chemical form of mercury $(\mathrm{Hg})$. $\mathrm{MeHg}$ is produced in aquatic ecosystems from deposited inorganic mercury $(\mathrm{iHg})$, and subsequently bioaccumulates and biomagnifies through the food chain. This causes large predators in the marine environment to ingest and accumulate large quantities of this element mainly in the form of MeHg. Antarctic Giant Petrels are the main scavengers in the Southern Ocean and particularly exposed to elevated levels of MeHg. Previous studies on seabirds in the southern hemisphere have revealed specific patterns of accumulation, distribution and biotransformation of $\mathrm{Hg}$ (Renedo et al., 2018; 2021). In spite of the high $\mathrm{MeHg}$ intake, it seems that the detoxification mechanisms present in these organisms are sufficient to protect them from severe degenerative damage. One of the main detoxification processes in the organism is the demethylation of $\mathrm{MeHg}$ and its interaction with selenium (Se) to form $\mathrm{HgSe}$ nanoparticles (NPs), which have been observed in different living organisms. However, little is known about the complete mechanism of $\mathrm{MeHg}$ detoxification to $\mathrm{HgSe}$ nanoparticles. This work sheds some light on the transformation mechanism by using the isotopic composition of $\mathrm{Hg}$ in different organs (liver, kidney, muscle, brain), blood and by isolation of HgSe NPs. The results suggest that in some key organs of Northern Gian Petrels the isotopic composition of $\mathrm{Hg}$ is consistent with that of the HgSe NPs. A high percentage of $\mathrm{MeHg}$ in the organ can be related to a bulk isotopic composition enriched in heavier isotopes with respect to the HgSe NPs. The shift for $\delta^{202} \mathrm{Hg}$ between bulk and $\mathrm{HgSe}$ NPs isotopic composition varies between 0.02 to $1.60 \%$ along the individuals in this study. Therefore, the isotopic composition of whole $\mathrm{Hg}$ pool in different tissues of Antarctic giant petrels reflects a mixture of the lighter $\mathrm{Hg}$ from the $\mathrm{HgSe} \mathrm{NPs}$ and heavier residual $\mathrm{MeHg}$ transferred to these organs via the bloodstream. This study is the first to report $\mathrm{Hg}$ isotopic compositions in $\mathrm{HgSe}$ NPs isolated from seabird organs.

Renedo et al., Chemosphere, 263, 2021.

Renedo et al., Environmental Science \& Technology, 52 (7), 4227-4234, 2018. 